\title{
Filosofia e beleza muntu-angolana
}

Patrício Batsîkama

Diretor do CEICA-ISPT (LuANdA, Angola)

Kwame Appiah fez uma releitura sobre a etnofilosofia e, partindo dos pressupostos também abordados por Hountondji, reflecte sobre os paradigmas nos quais o "eu negado" se insere 7 Como era de esperar, ele revisitou de algum modo a filosofia bantu de Placide Tempels. A necessidade de olhar os valores estéticos como fundamentos de filosofia da cultura em Áfricą2 alcança três campos: arte, crenças secularizadas e símbolos activicistas. No caso de Angola iremos optar comentar os exercícios principais que levam a filosofia: organizar informações, descrevê-las, compreendê-las para depois fazer uma análise que conduz à qualidade da ideia ou pensamento.

Se a filosofia é o exercício sistemático de conceitos, pensamentos e a capacidade lógica de explicar o mundo, ${ }^{3}$ importará compreender, antes de mais:

I. Os pontos funcionais da filosofia/conhecimento:

a) diferenciar o real do pensado a partir das informaçóes relativas à existência e ao ser;

${ }^{1}$ APPIAH, K. In my father's house. Nova York: Oxford University Press, pp. 85-106; HOUNTONDJI, P. Sur la philosophie africaine. Paris: Maspero, 1976.

${ }^{2}$ THOMPSON, R. F. Flash of the spirit: arte e filosofia africana e afro-americana. São Paulo: Museu Afro Brasil, 2OII.

${ }^{3}$ GYEKYE, K. African philosophical thought. Cambridge: Cambridge University Press, 1987; SALMON, W. C. Lógica. Rio de Janeiro: LTC Editora, 2010. 
b) reconstruir os pontos epistémicos tal como os muntu-angolanos os compreendem;

2. A arte e os seus conceitos pressupóem:

a) a lógica (uma vez que optaremos por uma definição lógica da arte);

b) as expressóes e modalidades artísticas, para compreender o que é arte endogenamente;

c) a filosofia da arte (uma sucinta comparação entre os conceitos ocidentais /indo-europeus e muntu-angolanos) como reflexão à volta da expressividade da arte, da sua função na existência e, sobretudo, da peculiaridade estética que o homem lhe atribui.

O conhecimento consiste em sistematizar várias informações, depois de uma análise dos seus conteúdos. A análise passa por: "sentir" e "descrever" para conhecer. Esta é a primeira fase do conhecimento. Depois, a segunda fase: "definir" para compreender a existência, o ser possível e o ser impossível. Isto é "definir o homem", uma auto-compreensão de si. Depois, a última fase: o que seria a "lógica", endogenamente. Isso nos pode proporcionar reconstruir o sistema metafísico que regula toda filosofia da arte, localmente.

Partindo do pressuposto que filosofar é sentir (perceber e compreender) e descrever (explicar e analisar) a existência - o que conduz a uma especialidade do saber na base da crítica - interessa olharmos como endogenamente esses dois exercícios são tidos entre os muntu-angolanos. ${ }^{4}$

\section{Sentir}

Sentir: sensação e inteligência são duas funções inevitavelmente unidas, mas tendo cada uma o seu papel e o seu poder 5 Tempels não fez essa diferenciação $]^{6} \mathrm{~A}$

${ }^{4}$ A cada vez que nos referimos a muntu-angolano, queremos dizer com isso: nyaneka, umbûndu, côkwe, mbûndu e kôngo.

${ }^{5}$ DEWEY, J. Art as experience. Nova York: Perigee Trade, 2005, p. 34.

${ }^{6}$ TEMPELS, P. La philosophie bantu. Paris: Présence Africaine, 1948, pp. 19-20. 
discussão seguiu com diferentes pensadores entre os quais os neotempelsianos.7

"Sentir" diz-se ivite, yiva ou livita, em nyaneka. Em umbûndu, temos ivaluka e yeva, que significam "saber", "perceber”, "conhecer”, "compreender", isto é, "sentir por meio dos sentidos" 8 Os Nyaneka e Umbûndu diferenciam lucidamente "sentir" de "conhecer", "sensação" de "inteligência”, pelo facto de ter um lote de palavras para designar "descrever" e "conhecer". (Ver ponto 2, a seguir)

$\mathrm{O}$ que produz a alegria e a dor é bem diferenciado na linguagem. Exemplos: ndi-ivite outala (estou a sentir frio), em nyaneka/umbûndu, e ngosindila mbâmbi, em kimbûndu. No entanto, "inteligência" é omunongo, omupongo que difere de sentimentos (afecção = ontheto, omutima). Trata-se de um exercício quantitativo de descrição, acto mental. 9 oposto à emoção, afeição. Por isso, a inteligência pressupõe "descrever" e "conhecer".

\section{Será que “descrever" é "conhecer"?}

"Descrever" corresponde, em nyaneka, às palavras tongonoma, potauyula, pokolola; ao passo que, em umbûndu, corresponde à palavra potolola, o mesmo que "descrever”, "desfazer”, “desenrolar”, “explicar”, “comentar”, “interpretar” etc. "Conhecer" corresponde, em nyaneka, às palavras noñgonoka, pongola, ponga ou ngonga; em umbûndu, corresponde à palavra pongoya, o mesmo que "afeiçoar", "aperfeiçoar", "conhecer”, ou ainda lôngisa, "ensinar”, também pungula, "discernir", "distinguir".

Em côkwe, "descrever" é um processo que dá sequência ao "conhecer" a coisa descrita. Esculpir significa "descrever”, "exprimir”. Recitar um poema épico é "exprimir" uma realidade sentida, vivida. Por essa razão, é muito comum ver "pokolola-descrever" ser confundido com pongolola-conhecer ${ }^{\text {IO }}$ Neste caso, onde

7 BIDIMA, J-G. Théorie critique et modernité négro-africaine: de l'École de Francfort à la "Docta spes africana”, Philosophie. Paris: Publications de la Sorbonne, 1993.

${ }^{8}$ GUENNEC, G.; VALENTE, J.F. Dicionário umbundu-português. Luanda: Instituto de Investigação Científica de Angola, 1972, p. 593.

9 CROS, E. Le sujet culturel: sociocritique et psychanalyse. Paris/Torino/Budapest : L'Harmattan, 2005, p. 74.

Io SILVA. Dicionário nhaneca-português. Lisboa: Junta de Investigações Científicas de Angola, 1966, p. I24. 
está a palavra pokolola deveria estar a palavra pongol(ol)a, "conhecer", "discernir", como causa de tongola. Ora, pokola faz pensar que o obânda (neófito) ainda esteja a aprender (através da descrição), o que não é correcto na cosmogonia muntu-angolana. Num Tribunal, o advogado deverá fazer prova de autocrítica ao descrever os factos. Isto é, ao "descrever" ele cumpre seguidamente com "analisar".

Em kikôngo, diz-se vokula, "desfazer, descrever, descortinar, dividir algo" mA versão côkwe é vùkula, "cortar fora", "decepar", "traçar" "' Na verdade, o facto de o ser humano agregar em si as componentes física e, simultaneamente, metafísica ${ }^{\sqrt{3}}$ fá-lo passar das experiências empíricas ${ }^{\sqrt{14}}$ para as observaçóes detalhadamente descritas (científicas). Só depois da (pré-)existência física é que ele integra a existência metafísica.

A máscara de mwâna pwo é uma descrição crítica da beleza. Associar símbolo da interdição do actor feminino a uma "menina bonita", é uma crítica da beleza entre o enunciado (beleza) e a realidade (simbolo da beleza) que pressupõe "descrever" e "conhecer" " $\mathrm{T}$ O treino - que a etnografia colonial chamou de iniciação mágica - é uma mistura de "descrever e conhecer". Dançar ciyanda pode melhor explicar isso. Embora o mestre de mukixi não recorre aos princípios e sistemas propriamente científicos, importa realçar que tem método, separa claramente as coisas. Os Angolanos pensam que a sua (pré-)existência física deve ser abundantemente material e imaterial para, depois da passagem física (morte), começar-se a existência. Voltaremos a este ponto mais adiante.

Edgar Morin tem chamado à ilusão, na construção do conhecimento. As especulaçóes (ilusóes $=$ ovi-vala ) em nyaneka/umbûndu se limitam aos aspectos da descrição: a distracção descritiva (kembela = enganar; ponya = erro de distracção). $\mathrm{Na}$ descrição e análise, o pensador imprime a sua subjectividade com as suas ilusões, tal como se aprende no mbôngi’a ñgîndu. É assim que acontece nas diferentes modalidades artísticas, entre os côkwe com a pintura parietal. Isso

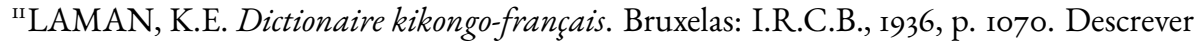
detalhadamente se diz tetumuna. Conhecer bem, saber bem é yîkula.

${ }^{12}$ BARBOSA, A. Dicionário cokwe-português. Lisboa: Junta de Investigações do Ultramar, 1989, p. 660.

${ }^{13}$ PLATON. CEuvres complètes, Flammarion, Paris, 2005 , p. II8.

${ }^{14}$ DEWEY, J. Art as experience. Nova York: Perigee Trade, 2005, p. 63.

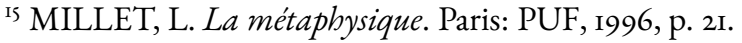


não muda em Platão, por exemplo, que considera a especulação com o funcionamento da inteligência. A Teoria das Ideias (Platão) lembra-nos de que a Ideia não é apenas aquilo que se faz na mente, mas a sua substancialidade material: a cadeira é Ideia desde que a sua descriçãoo esteja gravada na mente. Grosso modo, as linguagens muntu-angolanas têm diferenciado de forma clara o processo da cognição. Entre os Kôngo, existem linhagens e seus ndumbululu, "narrativa linhagética" ${ }^{16}$ Além de relatar a história da linhagem, cada narrativa tem estilo, argumento, discurso e uma ou mais reflexóes à volta deste tópico.

\section{Como é definido "homem"?}

Homem éomulume, geralmente, tido como sábio = ondongalume; omukwataviti, em nyaneka. No entanto, começamos com o termo mais genérico: omuntu (pessoa, indivíduo, independentemente do sexo). Este termo significa o possuidor de omu-twe (cabeça, conhecimento, inteligência, sabedoria, etc.). Em umbûndu, temos omu-ntu. É bom assinalar que $n t u$ (cabeça) deriva do verbo oku-tuwa, "habituar", "acostumar", "usar", no sentido de que ntu significa "motor que conhece e obedece nitidamente aos hábitos, costumes e usos”. Não foge à noção metafísica da inteligência-espírito no Ocidente $\underbrace{\sqrt{17}}$ isso é possibilitado pela socialização. Em kikôngo, tuwa significa "edificar algo ou alguém". A variante tubama é "encher até ao limite", ou seja, "perfazer", "estar na plenitude", "elevar”, "encher completamente" ${ }^{18}$ A construção da cabeça é uma questão de tempo, razão pela qual bituba significa também "tempo" ou "período". Quer dizer que omuntu é aquele que é "iniciado na sua plenitude", um deus em minúsculas, tal como Schopenhauer o mostrou na sua reflexão. ${ }^{19} \mathrm{O}$ bebé, omuñkayi-ntu ou omuñkabitwe é a "massa anatómica em processo da sua plenitude como pessoa (iniciada)". Por isso, o seu corpo é chamado de olu-beve, ebivivi. Só depois da iniciação é que a pessoa entra na sociedade e assume, em plenitude, a sua qualidade de

${ }^{16}$ CUVELIER, J. Nkutama mvilza za makanda mu nsi'a Kôngo. Tumba: Diocèse de Matadi, 1934.

${ }^{17}$ MILLET, L. La métaphysique. Paris: PUF, 1996, pp. 30; 43-44.

${ }^{18}$ Ver o dicionário de Laman (1936: p. 988).

I9 SCHOPENHAUER, A. Sobre a vontade na natureza. Porto Alegre: LPM, 20I3, pp. 39; 43. 
muntu. Mas nem com isso começa a existir "efectivamente"; ele ainda permanece na pré-existência ou na existência passiva.

A explicação mitológica da origem do homem (criação do mundo por Huku, Kalûnga $:^{20}$ Suku, Nzâmbi) liga a existência materia $\left.\right|^{27}$ à existência imaterial. A primeira está ao alcance do homem, sem recurso a terceiros, assim como o corpo, que, na verdade, não precisa de aparelho algum para evidenciar a sua existência: olu-tu é o corpo de uma pessoa viva, com os sentidos a funcionarem normalmente, razão pela qual ainda subsiste a partícula $t u$, tal como nos Kôngo, nitu. O corpo sem sentidos (cadáver, por exemplo) é endindi ou omutumba ${ }^{22}$ em umbûndu ou nyaneka, cuja variante kôngo é mvîm $\boldsymbol{b} i$, ou ainda $k \hat{\imath} \boldsymbol{m} \boldsymbol{b} i$, em kimbûndu. É diferente do corpo de uma criança (ebivivi) assim como do corpo de um animal (ovimpha). Confirmada a diferença entre "descrever" e "conhecer" nas actividades hodiernas dos muntu-angolanos, está claro que o homem (da meninice à velhice e morte) tem diferentes apelaçóes que o associam à Providência, cuja diacronia cognitiva corrobora a unidade e unicidade do homem: corpo e alma (ponto embrionário com a Providência). Todo o processo é definido pelo tempo ${ }^{23}$ o que significa que, tal como entre os côkwe, o ser humano é o resultado da experiência, a qual o torna, naturalmente, numa pessoa boa: thì. Segundo Barbosa, thì significa "condição (estado ou característica) do ser humano" e, ao mesmo tempo, "bondade", "humanidade" ${ }^{24} \mathrm{O}$ mesmo se verifica, também, entre os Kôngo, Umbûndu e Nyaneka.

${ }^{20}$ Em kikôngo, o termo kalûnga deriva do verbo lûnga, "ser suficiente", "ser completo", “justo”, "legal”, “estar correcto”, “exacto” etc. Ver o dicionário de Laman (1936:436).

${ }^{21}$ MILLET, L. La métaphysique. Paris: PUF, 1996, pp. 44-5I.

${ }^{22}$ A variante matûmba, em kikôngo, significa a "tomba mortuária”.

${ }^{23}$ PLATON. Euvres complètes. Paris : Flammarion, 2005, pp. 384-345.

${ }^{24}$ BARBOSA, A. Dicionário cokwe-português. Lisboa: Junta de Investigações do Ultramar, 1989, p. 608. 


\section{Como são diferenciados "existir", "ser possível" e "ser impossível”?}

"Existir", oku-li; "viver", oku-li-ko: "Ambalau eheneye k'ouye, ame ndyiliko-ale" ${ }^{25}$ Encontramos $l i$ em côkwe ${ }^{26}$ como também oku-kala, "estar", "residir" etc. Em umbûndu, é o mesmo; além do termo fwima (viver, respirar), oku-kala (estar) é preferido no uso. Oku-kala, que é usado em quase todas as populações angolanas, especifica que a missão humana consiste em existir, depois de acumular os ingredientes da compreensão da natureza $(=\tilde{n} t u, \tilde{n} t w e)$. Nessa óptica, o tempo é uma dimensão basilar da existência ${ }^{27}$ Em kikôngo, aliás, ku-kala significa: a) "ser", "viver", b) "existir", "restar" etc. Di-kala, portanto, quer dizer "tempo", ou seja, o tempo passado; por vezes é usado como advérbio ("há já muito tempo"). Exemplo: "kala kafwa" (já morreu há muito tempo). Tudo indica que ñtu, ñtwe seja produto do tempo ou ainda da longa existência $\left.{ }^{28}\right]$ razão pela qual o possuidor dessa compreensão da existência se chama muntu, omuntu, pessoa a priori boa, possuidora do motor do conhecimento da existência. Tal é somente possível depois de se diferenciar o "ser possível" do "ser impossível", uma outra tarefa que entra em vigor para se conhecer o próprio conhecimento.

"Ser possível" diz-se, em nyaneka, tavela, pondola; oku-tavelesa, "possibilitar". Em umbûndu, "ser possível" é oku-tava, ou seja, oku-tavisa, oku-taviya. Isto é, como diz Leibniz, "se Deus é possível, Ele existe”. Dois decursos distintos entre os muntu-angolanos. Esses termos opõem, tal como Kant, na sua Crítica da razão pura, o "possível lógico" o o "possível real": oku-taviya é o que está de acordo com aquilo que a natureza estabelece, o que leva as pessoas a crer; oku-tava depende de uma "experiência possível". Esta compreende também a "verdade necessária" (ocitaviya) e a "verdade de facto" (ocitava). Em kikôngo, ku-tabika significa "concluir o que é convencional", por isso, este deve ser protegido a todo o custo, tabila, "proteger", "salvar".

25 “Eu já existia antes de Abraão vir ao mundo”. SILVA, op. cit., p. 229.

${ }^{26}$ BARBOSA, op. cit., p. 27 I.

${ }^{27}$ SCHOPENHAUER, A. Sobre a vontade na natureza. Porto Alegre: L\&PM, 20I3, p. 45.

${ }^{28}$ MILLET. La métaphysique. Paris : PUF, 1996, p. 8; PLATON. Euvres complètes. Paris : Flammarion, 2005, pp. 379-397. 
"Ser impossível" é, em nyaneka, hapondola, hatavela, pona; impossibilitar, oku-vindamesa, oku-vindika, oku-cilika. Em umbûndu, o termo oku-vindamesa é "opor à natureza”, "opor ao que é permitido", sinónimo de yatava, que significa "deixar rasto", ou seja, "arrastar", no sentido de "sair de dentro da realidade", "desatar" (oku-likoka e oku-likokola). Na crença umbûndu (e angolana em geral), é o sinal daqueles que não observam os usos e costumes (ou seja, a natureza), aqueles que se desprendem das normas estabelecidas (convencionais). Oku-batavela quer dizer o que é "impossível consoante a experiência humana (possível)". $\mathrm{Na}$ versão côkwe, takika é "fazer algo, agir, comportar-se indevidamente, fora do normal" ${ }^{29}$ Os dois termos precedentes diferenciam-se fundamentalmente de -vindamesa, o que é "impossível em si", ou seja, contraditório. Aliás, entre os côkwe, yind ama quer dizer "tornar-se azarado" ou "ser atingido pelo infortúnio", "ser desafortunado" ${ }^{30}$ Isto é, a noção da impossibilidade está ligada intimamente ao infortúnio, uma vez que "ser feliz", "ser afortunado", corresponde à normalidade. Em relação à versão nyaneka, o prefixo infixo ha correlaciona-se com sufixo ila para indicar o contrário daquilo que é natural. Notamos que a natureza por si só é a felicidade, e pressupóe respeitar os usos e costumes que condicionam a felicidade. Quem os observa será feliz, e quem não os observa será infeliz. A observância das normas (respeitar a lei) é a felicidade, aproximando-se da definição ocidental/indo-europeia: "estado do que está feliz"; "bom êxito"; "boa fortuna". Os Ingleses têm happiness (joy); Glück, dizem os Alemães. Numa só palavra, o muntu é bondoso por ser instruído em ter e observar virtudes sob pena de, na ausência das mesmas, tornar-se anti-social.

O muntu é pessoa consciente, que o diferencia do animal. E, por outro, ela está ligada com a força criadora, Espírito de Nzzâmbi/Deus. Existe uma ligação ontológica entre Deus e o homem como forma de atribuir a este último o valor de "ser criador" " a partir do espirito no homem 3

Citemos, a propósito, Carlos Estermann屑

\footnotetext{
${ }^{29}$ BARBOSA, A. Dicionário cokwe-português. Lisboa, 1989, p. 56I.

${ }^{\circ}$ BARBOSA, A., op. cit., p. 712.

${ }^{3 \mathrm{I}}$ KAGAME, A. La philosophie bantou-rwandaise de l'être. Bruxelas: ARSOM, 1956.

${ }^{32}$ Homem é espírito, corpo, vontade/alma.

${ }_{33}$ ESTERMANN, E. Etnografia do sudoeste de Angola. I. Os povos não-bantos e o grupo étnico dos ambos. Lisboa: Junta de Investigaçóes do Ultramar, 1956, p. 213.
} 
Para designar a divindade suprema, existe uma vasta área linguística que compreende, além dos Ambós, os Nyaneka-Nkûmbi, os Herero, o bloco Ngangela, os Umbûndu e até os Côkwe. Em todas estas línguas, o radical verbal -lunga exprime sempre algo de relacionado com a inteligência. Em kwanyama, o radical simples emprega-se raras vezes em prosa, por ser considerado forma arcaica. Mas, tanto em prosa como em poesia, ele tem o significado do composto -lunguka, que quer dizer "ser astuto", "ser esperto". Noutros idiomas, o verbo oku-lunga significa "estar atento", "vigilante”. Além disso, todos os idiomas deste grupo linguístico contêm o substantivo ndunge.

Como podemos verificar, Deus personifica a consciência e a inteligência juntas. Como veremos adiante, o homem, descendência cosmogónica de Deus, descende naturalmente da consciência cósmica e, também, da inteligência celestial, reflectida na sua condição de criador enquanto pessoa/muntu. Daí, toda a pessoa/muntu - enquanto símbolo - é, logo à partida, a antropomorfização da inteligência/consciência.

\section{O que é a "lógica" entre os muntu-angolanos?}

O conceito de lógica, no sentido em que foi definida pela historiografia ocidental ${ }^{34}$ está relativamente presente nas produções artísticas angolanas. Confunde-se primeiro com juízo (omundunge, onotheso e onunkengela), depois com verdade, ou seja, oci-ili em contraste com a razão, omundunge (onotheso, onunkengela). Guennec e Valente escrevem ukulibiso wulondunge como tradução literal da palavra lógica, sendo o lógico sunguluka ("o que é racional”) ou tyama k’ondunge ("pertencente ao raciocínio") 菏 Curioso ainda é o facto de verdade e razão se confundirem com o sentido que os europeus dão às palavras "lógica” e "juízo" (Aristóteles): wulundunge, por exemplo, é um juízo apodíctico, já que se confunde com a razão, ou seja, "juízo que convence verdadeiramente (pela razão)".

${ }^{34}$ HEGENBER, L. Dicionário de lógica, São Paulo: E.P.U., I995, pp.I20-I3I; DIDEROT, D. Euvres complètes, 1976, pp. 2II-217.

35 GUENNEC, G.; VALENTE, J.F. Dicionário umbundu-português. Luanda: Instituto de Investigação Científica de Angola, 1972, p. 380. 
$\mathrm{Na}$ linguagem de Kant, é juízo técnico-prático (habilidade), que difere de juízo pragmático (prudência); onunkengela é a tradução (talvez) perfeita do "juízo de valor”. Se perguntar ao muntu-angolano "porque prefere os santos (bons espíritos)", as respostas podem variar: a) porque são os modelos da harmonia social; b) porque assim vai-se para o mundo de Deus. As respostas a) e b) são juízos subjectivos objectivados (onunkengela). As respostas (juízos) não são baseadas na experiência existencialista, mas sim na experiência essencialista, o que é ligeiramente diferente na tradição aristotélica e cartesiana; Kant chamou-a de juízo moral-prático. Podemos acrescentar os juízos apofânticos: ova-iliso confunde-se com onotheso. Infelizmente, muitos dos tradutores de línguas africanas de Angola não souberam diferenciar, de modo que só podiam traduzir por conveniência. Aliás, não se pode perder de vista que o objectivo de compor lexicografias em línguas africanas tinha interesses práticos: conhecer melhor os povos para melhor os colonizar. Registaram-se - na colonização portuguesa - poucos trabalhos científicos consistentes e de excelência.

Mas se existe um termo que os Nyaneka, Umbûndu e Côkwe possam entender por lógica - que fique claro que não estamos aqui a traduzir literalmente - esse termo pode ser sunguluko. Todos os juízos que acima tentámos traduzir fazem parte de sungulako, ou seja, da "conjectura do pensamento válido". A palavra sungulako deriva do verbo sunguluka, que, em umbûndu, significa "ser recto; ser justo; ser compreensível”, de acordo com o reverendo Daniel Etaungo; ou seja, sungulukila, em côkwe, significa "ser legítimo; ser afável; ser inteligível”; sungulwisa, "explicar, interpretar inteligivelmente; instigar". Barbosa menciona ainda sungama, "estar recto, apurado"; sungula, "prestar atenção" ${ }^{36}$ Guennec e Valente tiveram a felicidade de traduzir correctamente a palavra lógica por sungulako. Entre os Kôngo, lógica continua a ser sung(ulak)u ${ }^{37}$

$S$ é $\mathrm{P}$ (juízo afirmativo) e $S$ não é $P$ (juízo negativo), que herdamos da tradição aristotélica (lógica clássica), são dois exercícios de sungulako entre os muntuangolanos. No Tribunal o advogado faz uso, com retórica. Na dança jimba (entre os Umbûndu), a expressão corporal é argumento por si e varia consoante as ilusóes de quem orienta dançar (pode ser batuque, salva de palmas ou som ouvido).

\footnotetext{
${ }^{36}$ BARBOSA, A. Dicionário cokwe-português. Lisboa, 1989, p. 543.

${ }^{37}$ LAMAN, K.E. Dictionaire kikongo-français, 1936, pp. 926-927.
} 
A dança pode ser usada como diálogo, quando se quer omitir informação aos estranhos. Ali, cada advogado-dançarino gesticula consoante sua própria ilusão.

Como podemos notar, não é justo excluir os africanos em geral - e os angolanos em particular - da cidadania filosófica. A produção herdada, assente na língua, demostra que obras de arte (pintura, escultura, gravura, dança, som articulado, som musical etc.) que encontramos nos museus são possuidoras de pensamento fino, bem estruturado que pressupóem espaço filosófico. Os muntuangolanos dominam as noções basilares para uma estrutura filosófica. Isto é, a partir da arte que a etnografia considerou feitiço, é possível perceber que haja um discurso filosófico estruturado.

Alguns pensadores postulam a necessidade da presença das diversas escolas filosóficas, das suas sistematizaçóes e, acima de tudo, de algo escrito: $3^{3^{8}}$ tal como foi na Grécia antiga 39 As iniciações (de puberdade ou profissional, etc.) são autênticas escolas. O mbôngi, entre os Kôngo, era uma escola para ciências políticas com carga de filosofia.

\section{O que significa "filosofia"?}

Começamos por citar Ewing 40

Uma definição precisa do termo filosofia é impraticável. Tentar formulá-la poderia, ao menos de início, gerar equívocos. Com alguma espirituosidade, alguém poderia defini-la como "tudo e nada, tudo ou nada (...)” Contudo, na prática, o conteúdo de informação real que a filosofia acrescenta às ciências exactas tende a desvanecer-se até parecer não deixar vestígios. Acreditamos que esse desvanecimento seja enganoso. Mas, devemos admitir que até aqui a filosofia não tem conseguido realizar suas grandes pretensões. Tampouco ela

${ }^{38}$ KAGAME, A. La Philosophie bantou-rwandaise de l'être. Bruxelas: ARSOM, 1956, pp. $74 ; 8$.

${ }^{39}$ EWING, A.C. As questóes fundamentais da filosofia. Rio de Janeiro: Zahar, I984, pp. II25 .

${ }^{40}$ Ibid., p. II, grifos nossos. 
tem logrado êxito em produzir um corpo de conhecimento consensual, comparável ao elaborado pelas diversas ciências. Isso se deve em parte, embora não integralmente, ao facto de que quando obtemos conhecimento verdadeiro a respeito de determinada questão, situamos essa questão como pertencente à ciência e não à filosofia. O termo filósofo significava originariamente amante da sabedoria, tendo surgido com a famosa réplica de Pitágoras aos que o chamavam de sábio. Insistia Pitágoras em que sua sabedoria consistia unicamente em reconhecer sua ignorância, não devendo, portanto, ser chamado de sábio, mas apenas de amante da sabedoria. Nessa acepção, sabedoria não se restringia a qualquer dos domínios particulares do pensamento e, de modo similar, filosofia era usualmente entendida como incluindo o que hoje denominamos de ciência. Esse uso sobrevive ainda hoje em expressóes como filosofia natural. $\mathrm{Na}$ medida em que uma grande produção de conhecimento especializado a um dado campo ia sendo conquistada, o estudo desse campo se desprendia da filosofia, passando a constituir uma disciplina independente.

\section{Já Nietzsche escreve: $:^{41}$}

Os Gregos, enquanto povo, verdadeiramente são, justificaram a filosofia de uma vez para sempre, pelo simples facto de terem filosofado; e mais do que todos os outros povos.

Etimologicamente, "filosofia" deriva de philo (filo), amor, ou seja, "eu amo", e sophia (-sofia), que significa "sabedoria"; literalmente, amor pela sabedoria. Enquanto palavra, não a encontramos (no terreno) nas línguas angolanas. Mas o seu exercício (entre os Angolanos) é amplo, quer durante os julgamentos, quer nos debates relacionados com assuntos públicos, ou mesmo religiosos. Portanto, nas lexicografias consultadas, encontramos alguns indicadores:

- Umbûndu/Côkwe/Nyaneka:

${ }^{4 \mathrm{I}}$ NIETZSCHE, F. A filosofia na época trágica dos gregos. Lisboa: Edições 70, 2006, p. I8. 
I. Ulisole lya unongo

2. Ocisoliso ulongo

\section{Sola unongo}

4. Sola okulibiso (ocisoliso lya ukulibiso).

De todas as traduções que pudemos encontrar em Guennec e Valente, os pontos 2 e 4 são reveladores. No ponto 2, ocisoliso é “amor”, deriva de solisa (sola), "fazer amar" (sola, amar, agradar, preferir). Em côkwe, sola quer dizer, de acordo com Barbosa, "ter ou sentir desejos de carne ou peixe": phwó ufumba anasólela, isto é, a mulher está ougada devido à gravidez ${ }^{42}$ Quanto ao ulongo, tal como vimos atrás, significa sabedoria como fruto da educação, no verdadeiro sentido grego ${ }^{43}$ A versão côkwe é muito reveladora: longa, "ser", "tornar-se alinhado", "em ordem", "em conformidade ou em harmonia”, “portar-se bem” depois da educação, uma vez que a mesma palavra (longa) se traduz por "educar”, "instruir”, "preparar para a vida" ${ }_{44}^{4}$ Salientemos que muntu é a pessoa realizada (educada), razão pela qual sabedoria se confunde com o processo da educação. Aliás, ulongo como sabedoria deriva de longa, "educar", "instruir", e não de "saber", que se diz hina, kulibisa, como alguns autores preferem. Convém assinalar que o verbo monga quer dizer "perceber”, embora não influencie em quase nada a formação do termo ulongo. O L é lingual, enquanto o M é bilabial. Apesar de ser uma raridade notória, a metamorfose do L em M não é impossível. Exemplo: lunda $($ montanha $)=$ munda $/$ kamunda $($ pequena montanha $)$.

Literalmente, porém, oci-soliso ulongo traduz-se como a) "amor ao conhecimento"; b) “amor à aprendizagem”, mas nunca como "amor à sabedoria”, uma vez que a noção semântica de "sabedoria" nos Umbûndu liga estreitamente o conhecimento à aquisição de conhecimento com o tempo, tal como na concepção muntu-rwandesa ${ }^{45}$ A sabedoria como a entendem os ocidentais/indo-europeus

${ }^{42}$ BARBOSA, A. Dicionário cokwe-português. Lisboa, 1989, p. 523.

${ }^{43}$ PLATON. Euvres complètes. Paris : Flammarion, 2005, pp. 29-39.

${ }^{44}$ BARBOSA, A. Op. cit., p. 283.

${ }^{45}$ KAGAME, A. La philosophie bantou-rwandaise de l'être. Bruxelas: ARSOM, 1956, pp. 19; 37. 
não existe concretamente entre os vivos, pensam os muntu-angolanos, que a atribuem ao Deus chamado Kalûnga (possuidor da inteligência, da sabedoria, omnisciente). Curiosamente, essa atitude foi também assumida por Pitágoras, o primeiro filósofo, ao recusar ser considerado sábio e ter aceitado ser chamado de amante da sabedoria, isto é, filósofo.

Quanto a oci-soliso lya ukulibiso, a sua equivalência literal é "amor ao conhecimento", no sentido de "amor pelas noçôes concretas", ${ }^{46}$ O termo ulukiliso significa "conhecimento adquirido na escola e pela experiência". Deriva do verbo kulibisa, "tornar conhecido", "fazer saber", "adquirir conhecimento" ${ }^{47}$ Há duas propostas com ideia concisa de filosofia: I) oci-sola ukulibiso; 2) oci-sola-ukulibiso. A versão ocisola-ukuliso tornar-se-á ocisolakuliso para dizer "filosofia”. Por outro, oci-sola ulongo pode, por princípio de contracção, tornar-se oci-solalongo; logo, "filosofia" engendra oku-solalonga, "filosofia". Esse termo é logo percebido como filosofia, localmente, para os falantes de umbûndu, e não só.

Em kimbûndu, "amar" é zôla e "sabedoria" diz-se wijiba (uijiha). A morfologia de wijiha descreve-se da seguinte maneira: $b u-i / j i / h a ́$. É variante de kuliso, bu, sendo variante de $k u$; o $i$ é variante de $l i$; $j i$, que é dental, justifica-se como outras dentais, como $z i$, si; finalmente, o bá, que pode ser $k a$. Assim sendo, teremos kulisika, que também existe no kimbûndu de Nambwa Ngôngo, para dizer a mesma coisa: "saber", "conhecer" etc. A versão umbûndu seria zola kulisika, variante de zola-wijiya. Também temos zola longesa pode ser "filosofia", tanto como zola-long(es)a.

Passemos agora para os Kôngo. Na escola mbôngia ñgîndu, havia uma disciplina prática chamada mwêsa buzayi, cuja variante na sociedade secreta Lêmba era mpyându mazâya..$^{48} \mathrm{Em}$ ambas as instituições, os discípulos (inscritos) são chamados de matola, o "curioso" ${ }^{49} \mathrm{Na}$ verdade, $m$ wêsa quer dizer "explicar claramente" ao passo que buzayi é "sabedoria profunda"; mpyându é uma instrução qualitativa e mazâya é ciência, em geral, e "ciência da sabedoria" especificamente. Somos de opinião que os ambos termos tenham designado filosofia. Dentro

\footnotetext{
${ }^{46}$ DIDEROT, D. CEuvres complètes, Tomes V-VIII. Paris: Herman, 1976, p. 27.

${ }^{47}$ ALVES, A. Dicionário etimológico bundo-português, 195I, p. 38.

$4^{8}$ LAMAN, K. E. Dictionaire kikongo-français. Bruxelas: I.R.C.B., 1936, p. 87.

${ }^{49}$ Aquele que pergunta, o curioso. LAMAN, Dictionaire kikongo-français, 1936, p. 507.
} 
de mwêsa buzâyi havia lusânsu "método da instrução, da educação". Tendo a filosofia como fim "proporcionar" um "pensamento bem organizado" 50 a sua equivalência seria mwêsa buzâyi tenha a ver com a filosofia.

Como podemos ver, os termos que acabamos de apresentar nas línguas angolanas vêm provar aquilo que o padre Placide Tempels terá escrito: "Todo o comportamento humano se baseia num sistema de princípios" [2] Isto é, ao sistema de princípios, sendo possível, não poderá faltar os termos específicos em línguas africanas. Os contra-argumentadores de Tempels apoiam-se, na maior parte, na observação de Ewing (1984), cuja filosofia se baseava essencialmente na moral ${ }^{53}$ Mas o problema é que quem lê Alfred Cyrill Ewing hoje em dia consegue perceber que as épocas mudaram A4 África ainda é considerada, nessa época, exótica, inabitável, porque desconhecida, quer por colonizadores, quer pelos próprios filhos do continente, que ainda não dispunham de instrumentos científicos e de instituições académicas com sólida experiência e indubitável reconhecimento. Comecemos por citar Ewing:

Recusamo-nos a considerar filosóficas as questôes cujas respostas podem ser dadas empiricamente. Não desejamos com isso sugerir que a filosofia poderá acabar sendo reduzida ao nada. Os conceitos fundamentais das ciências, da figuração geral da experiência humana e da realidade (na medida em que formamos crenças justificadas a seu respeito) permanecem no âmbito da filosofia, visto que, por sua própria natureza, não podem ser determinados pelos métodos das ciências especiais. É sem dúvida desencorajador que os filósofos não tenham logrado maior concordância com respeito a esses assuntos, mas não devemos concluir que a inexistência de um resultado por todos reconhecido signifique que esforços foram realizados em vã ${ }^{55}$

so Racionalismo, misticismo. SPINOZA, Ethique, II, p. 43.

${ }^{5}$ Mpânda mazâya relaciona-se com "ciências humanas".

52 TEMPELS. La philosophie bantu, Paris: Présence Africaine, 1948, p. I4.

53 Ewing foi premiado com o Green Prize em Filosofia Moral, além de ter sido professor auxiliar, em 1954, da cadeira de Ciência Moral em Cambridge.

${ }^{54}$ BIDIMA, J-G. Théorie critique et modernité négro-africaine: de l'École de Francfort à la "Docta spes africana”, Philosophie. Paris: Publications de la Sorbonne, I993, pp. 78-79.

"EWING, A.C. As questôes fundamentais da filosofia. Rio de Janeiro: Zahar, 1984, p. I3. 
Voltemos a Placide Tempels para compreender a intenção linguagética $\sqrt{66}$

Não existe comportamento vital sem um sentido da vida; não há vontade de vida sem conceito vital; não existe constância prática salvadora sem filosofia da salvação... Será que devemos admirar o que encontramos nos Bantu, e mais geralmente nos primitivos, como fundamento das suas concepçôes intelectuais do universo alguns princípios de base e mesmo um sistema filosófico, relativamente simples e primitivo, derivado de uma ontologia logicamente coerente?

Tal discurso não podia agradar à ortodoxia filosófica na Europa 57 Aparentemente, este projecto tempelsiano - que em princípio partiu de um exercício filosófico - terá sido desde logo misturado com as sequelas de racismo (às vezes o tribalismo), a ponto de se ramificar nas instituições sociais ${ }^{8}$ e nas infra-estruturas cognoscitivas humanas. Pela novidade, o debate empobreceu-se em venerar o autor $\sqrt[59]{ }$ tal como o fez Alioune Diop. ${ }^{60}$ ou passando por uma retórica quase infrutífera 6

Decerto que a filosofia não se limita apenas a expressóes escolásticas ${ }^{62}$ a tratados sistemáticos ou a livros volumosos e lições ou conferências nas universidades sem antes estar presente no comportamento humano ${ }^{63}$ E se mesmo assim fosse, encontramos em África as expressões escolásticas (no caso de mpovi - advocatura entre os Kôngo e Umbûndu) em livros (pensamentos escritos em panelas,

${ }^{56}$ TEMPELS. La philosophie bantu. Paris: Présence Africaine, 1948, p. I5.

57 Bachelard, Gabriel Marcel, Lavelle, Jean Wahl, Georges Gusdorf etc.

${ }^{8}$ BIDIMA, J-G. Théorie critique et modernité négro-africaine: de l'École de Francfort à la "Docta spes africana", 1995, p. I03.

59 TOWA, M. Essai sur la problmématique philosophique dans l'Afrique actuelle. Yaoundé: CLE, 197I, p. 8I.

${ }^{60}$ Foi ele que editou o livro, na edição francesa, pelas edições Présence Africaine, em 1949.

${ }^{6}$ MUDIMBE, V. Y. The invention of Africa: gnosis, philosophy, and the order of knowledge. Bloomington: Indiana University Press, 1988, pp. 78-104.

${ }^{62}$ HOUNTONDJI, P. Sur la philosophie africaine. Paris : Maspero, 1976.

${ }_{63}$ TOWA, M. Essai sur la problmématique philosophique dans l'Afrique actuelle, Yaoundé: CLE, I97I. 
grutas, pinturas parietais, etc.) e institutos de formação (nzo'a lusânsa). Falta apenas traduzir tudo isso com maior prudência, respeitar a própria expressão muntu-angolana $\sqrt{64}$ e evitar veicular o pensamento africano consoante um sistema que não é africano. Talvez seria melhor escrever em línguas africanas o sistema africano para depois traduzi-lo para o uso dos não-africanos.

\section{Arte, artista: definição}

Assim lemos no dicionário: arte é

I) aplicação do saber à obtenção de resultados práticos (arte militar, por exemplo); 2) conjunto de processos, mais ou menos ordenados, para atingir um fim; 3 ) actividade de produção de coisas belas. ${ }^{65}$

Estas definições não fogem da posição de São Tomás de Aquino ${ }^{66}$ Dada a flexibilidade nocional de arte e artista, o que leva muitos especialistas a chamar tudo e todos de arte e artista, tentaremos redefinir estes termos, a fim de não se cair de novo num esvaziamento ou na possível banalização da arte. Estetas e filósofos ${ }^{67}$ já o tentaram fazer. Morris Weitz (1968) apostou fortemente nos fundamentos do existencialismo para definir a arte e fez comparações. Por sua vez, George Dickie fundamentou-se nos aspectos influenciadores da arte, que, afortunadamente, explicavam a essência da arte. E notamos nas suas argumentações alguma insuficiência ligada à própria evolução das ciências que estudam a arte. Nenhum deles definiu, pensamos, satisfatoriamente o termo, admitindo, porém, a impossibilidade de uma só definição globalizante.

A arte surgiu logo nas primeiras sociedades humanas, quando o ser social tentava superar as suas dificuldades, atenuar as suas inquietaçóes, ou tentava atingir

${ }^{64}$ VAZ, J. M. Filosofia tradicional dos Cabindas através dos seus cestos de panelas: provérbios, advinhas, fábulas I. Lisboa: Agência Geral do Ultramar, 1959.

${ }^{65}$ COSTA, et al., Dicionário de língua portuguesa. Porto: Porto Editora, 1998, p. I6I.

${ }^{66}$ BIGONGIARI, D. (ed.), The political ideas of St. Thomas Aquinas. Nova York: Hafner, I963, p. 210.

${ }^{67}$ DICKIE, G. "What is art?". In: AAGAARD-MOGENSEN, L. (ed.), Culture and art. Atlantic Highlands, N. J.: Humanities Press, 1976. 
um objectivo ao transformar a natureza, através da habilidade de transformar o que é natural ${ }^{68}$

De acordo com a teoria de Étienne Soriau, existem sete grupos de arte, nomeadamente:

I. Linhas: desenho, caligrafia

2. Volume: escultura, arquitectura

3. Cor: pintura, gravura, fotografia

4. Movimento: dança, teatro

5. Sons articulados: eloquência, declamação

6. Sons musicais: ópera, filarmónica

7. Animação: cinema, etc.

A partir desta proposta, como definiríamos arte, considerando todas essas modalidades?

A palavra "arte" em arménio significa "criação". Todas as modalidades da arte têm em comum uma certa morphos (forma), assim como mensagem (conteúdo) e título. Esse sentido fica mais claro em kikôngo, kiñkete: arte. O verbo kêta significa: "fazer algo belo" ${ }^{69}$ que envolve mwêsa e mpwe.70 Isto é arte pressupóe inteligência, simetria, beldade. Realçar que o termo mpwe designa beleza, fineza, harmonia $7^{7}$ elegância, por um lado. E, por outro, associa-se a nyênya: magnificência, sumidade, sumptuosidade, ${ }^{72}$ amenidade, ordem. Quando os côkwe dizem pwo a ideia principal é a beleza enquanto resultado da inteligência. Assim sendo, a "arte é toda obra cujo conteúdo e forma em congruência com o título constitui

\footnotetext{
${ }^{68}$ MILLET, L. La métaphysique. Paris : PUF, 1996, pp. 29-43.

${ }^{69}$ LAMAN, K.E. Dictionaire kikongo-français, p. 234.

70 Mpwênya, escreve Laman (1936: 59I). O termo significa, também, agradável, brilhante, lúcida etc.

${ }^{71}$ Outro termo para harmonia-beleza é lêko. LAMAN, I936, p. 388.

${ }^{72}$ LAMAN, K.E. Op. cit., p. 443,
} 
uma criação”. E isto não exclui África, de modo geral. Daí, a fórmula lógica seria a seguinte: $\alpha=[\{\zeta \leftrightarrow \phi\} \equiv \theta] \neq \mathrm{a} \cdot \mathrm{T}^{73}$

Esta definição parece-nos fiel à origem da arte, que

reside nos sentidos, na memória e no mimetismo; no entanto, a entrada em acção destas faculdades sob forma da arte, a exteriorização destes estados de alma reclamam elas próprias uma explicação e uma coordenação $7^{74}$

Do ponto de vista da etimologia, a fórmula ganha mais substância, sobretudo, se tivermos em conta o real sentido (episteme) da "coisa". A noção epistemológica de "arte" supõe uma ordem a qual o artista segue rigorosamente para que a sua obra assim seja denominada. Émile Benveniste, falando do direito/lei, escreve: "todas as sociedades [...] são regidas por princípios de direito quanto às pessoas e aos bens". E continua, dizendo que é "um conceito extremamente importante aquele de 'ordem'. É representado pelo védico $\boldsymbol{r t a}$ (avistica ăa uma evolução particular)": 75 Vamos deixar o autor falar: ${ }^{76}$

Todas as raízes se ligam à raiz ar-, bem conhecida pelas numerosas formaçôes fora do indo-iraniano e que se juntam a mais categorias formais precedentes. A raiz é aquela do grego ararisko, "ajustar, adaptar, harmonizar" (arménio arnel, "fazer"), à qual se juntam muito mais derivados nominais: com -ti-, latim ars, artis, "disposição natural, qualificação, talento"; com -tu-, latim artus, "articulação", e também com uma outra forma de radical, latim ritus, "receita. 77 rito"; grego artus (arm. ard, genitivo $a r d u$, "prescrição", assim como o presente artúnō, "arranjar, equipar"; com -dbmo-,

${ }^{73}$ Suponhamos que $\alpha$ significa arte, $\zeta$ é o conteúdo, $\phi$ simboliza a forma e, finalmente, o título $\theta$. O símbolo de $\equiv$ reporta à congruência.

${ }^{74}$ Herber Bayer assim definiu (exposição no Metropolitan Museum of New York).

75 BENVENISTE, E. Les vocabulaires des institutions indo-européenes. Paris: Seuil, 1975, pp. 99-IOo.

${ }^{76}$ BENVENISTE. Op. cit., pp. IOo-IOI.

77 Receita, isto é, fórmula, prescrição, indicação. 
grego arthmós, "ligação, junção"; com -dbro-, grego ártbrom, "articulação, membro", etc.

Quem é artista? Qualificado de divino pelos seus contemporâneos, Michelangelo, respondendo a Francisco de Holanda (I538-I540), disse:

Até no Velho Testamento quis Deus Padre, que os que houvessem somente de guarnecer e pintar a arca foederis [Arca da Aliança] fossem mestres não somente egrégios e grandes, mas ainda tocados da sua graça e sabedoria, dizendo Deus a Moisés que ele lhes infundiria sapiência e inteligência do seu espírito para poderem inventar e fazer tudo quanto fazer e inventar pudess $e^{7^{8}}$

$\mathrm{Na}$ acepção muntu-angolana, a noção definicional do "artista" como criador apega-se na figura de Deus com oito principais atributos a partir dos quais desenhase o arquétipo do artista primordial: Ñzâmbi (mansidão), Kalûnga (inteligente) e Mpângale (fabricador) relacionam-se com um Deus-filósofo. Sendo também Suku, Tûku (causa), este Deus criador/filósofo é também "elite". E, finalmente, o Deus muntu-angolano denominado Mvile (“começo"), Kumbi (“sol”) indica um Deus intelectual. Michelangelo, como já mencionámos, partilhou essa opinião, nos diálogos de Roma, de que o artista é filósofo, elite e intelectual. Assim sendo, construímos o pressuposto segundo o qual o artista deverá ser, ao mesmo tempo, filósofo, elite e intelectual.

Filósofo O artista é, antes de mais, um filósofo. Por outras palavras, ele é uma ideia corporificada (embodiement) e um objecto de referência. De facto, investiga e procura a verdade, tendo acesso às informaçôes que acha correctas. ${ }^{79}$ A obra que o artista cria (enquanto filósofo, ${ }^{80}$ não é bela a priori. É produto de uma inteligência que o espectador contempla/admira, e no qual o autor projecta a

${ }^{78}$ HOLANDA, F. Diálogos de Roma. Lisboa: Livros Horizonte, 1984, p. 60.

79 DEWEY, J. Art as experience. Nova York: Perigee Trade, 2005 , p. 52.

${ }^{80}$ José Júlio Lopes abordou esta questão na sua comunicação apresentada no colóquio "A Estética a partir da Música”, que foi promovido pela Associação dos Professores de Filosofia, Câmara Municipal de Matosinhos, abr. 2002. 
imaginação. A ideia de kalûnga reside em quatro presunções: precisão, virtudes e sabedoria ${ }^{81}$ Associa-se a arte - nkête - uma vez que na concepção muntuangolana, traz a ideia de honestidade, virtude, beldade na pessoa que pratica a arte com capacidade de suster um discurso simétrico (lógico) como argumento estético sobre questôes sociais.

Elite Por si só a obra expressa, por um lado, a autoridade profissional do seu autor em convergência com o contexto racional da época; por outro, testemunha sempre a ideia principal do seu autor como símbolo da sua época e para as épocas posteriores. Logo, o executor/artista torna-se elite pela perpetuidade do simbolismo estético da sua obra; mesmo a posteriori - no caso de Van Gogh, por exemplo -, essa notoriedade é reconhecida pela distinção que impóe entre várias propostas. A escultura do ñkîsi nkônde é, em princípio, um bom exemplo. Ela personifica a primeira autoridade com os símbolos do herói épico da sociedade lwângu, instaurador da moral social. Por essa razão, ainda é lembrado como um $\tilde{n} k \hat{s} s i$ (algo sagrado) para escorraçar os espíritos maus.

Intelectual Ñkûlumbi designa, em kikongo, pessoa idosa que aplica seu conhecimento para defender os injustiçados contra os excessos de autoridade. Nos côkwe, utiliza-se a todo habilidoso profissional com moral insurgir contra injustiça social, principalmente na arte. Os Nyaneka associam essas qualidades ao pintor, omulombi ${ }^{82}$ Émile Zola é um exemplo de intelectual. A crítica artística é sempre futurista, às vezes mal compreendida no presente. Não lhe basta apenas coragem para denunciar os erros ou fazer crítica, mas sim, e sobretudo, a faculdade de construir um programa-solução e nele participar activamente.

${ }^{81}$ LAMAN, Dictionaire kikongo-français, 1936, p. 437. O verbo lûngalakana significa: ser sábio, inteligente, muito racional.

${ }^{82}$ SILVA, A. J., Dicionário nhaneca-português, Lisboa; Junta de Investigaçôes Científicas de Angola, 1966, p. 434. "O pintor é artista, já se vê”, traduz-se por "Omulombi watyo omungo, cimonek'ale". 
Assim, o artista é, ao mesmo tempo, filósofo, elite e intelectual. Se fosse apenas filósofo, não seria chamado de artista ${ }_{33}^{83}$ Do ponto de vista da estética, a arte começa pela pseudo-arte, passa depois por quase-arte, ou simili-arte, para finalmente ser arte. Se for tecnicista, será chamado de artesão/pseudo-arte. Quando as obras começarem a expressar a idiossincrasia do seu autor, passam para quase-arte. Somente quando reunir todos os critérios (filósofo/elite/intelectual), será artista. Salientamos que embora esta classificação parta de uma historiografia ocidental, a mesma verifica-se noutros cantos do mundo, daí a compatibilidade com o sistema muntu-angolano.

\section{Será que existe o substantivo "arte” em linguas angolanas?}

\section{"Arte" entre os Nyaneka}

Evitando traduzir a palavra "arte” na sua singularidade semântica, vamos primeiro procurar saber como os nyaneka designam as manifestaçôes artísticas: dança, música, teatro etc.

I. Dança: no sentido de "brincar", temos nyana; "aprendizagem lúdica" é ondyongo ou omasakalunga. Existe também um termo genérico que é ocinyano ou, outra variante, ocidano.

2. Cântico: ociimbo, ocisungu. A música é igualmente sons articulados, pois significa "voz": (i) ondaka onene, "voz ou música grave"; (ii) ondaka onthutu, "voz ou música aguda".

3. Onde há música (coro) e dança é porque, segundo Aristóteles, há teatro. O termo theatron significa "espectáculo" e "edifício onde se realiza esse espectáculo”. O rito (coro e dança) passa a ser espectáculo-espaço que se diz ocimo e depende do tipo de ritos ${ }^{84}$

${ }^{83} \mathrm{O}$ carvão que se encontra dentro do lápis é um bom condutor de electricidade. Ora, não é tido como metal, dado que, geralmente, os metais são bons condutores de electricidade. Nesta mesma lógica, é artista somente aquele que é filósofo, elite e intelectual. "rito".

${ }^{84}$ Mas, geralmente, os termos oviso, ociso, ocikona, elikwatelelo são genéricos para designar 
4. Escultura: esculpir confunde-se com gravar, yola, sola, ou seja, honga e significam "fazer uma escultura e desenhar nela", ou no caso de outro suporte (ferro, cerâmica, cesto, por exemplo), "gravar” com semelhantes morfologias.

5. Pintura: ocilombi. "Pintar", em nyaneka, diz-se lomba, undisa - bona. .5 $^{5}$ A frase "Sabes pintar casinhas?" traduz-se por "Utiyivila okulomba ovimbala?".

São estes alguns dos termos que designam as modalidades artísticas. Preferimos falar de modalidades para I) respeitar a classificação estética da arte; 2) compreender o valor semântico de cada modalidade. As cinco modalidades trazem de forma convergente, a ideia de beleza (prática/teórica), grandeza, ordem, harmonia, simetria como suportes que evidenciam uma criação singular. Elas diferem e convergem de forma simultânea, o belo (ebiwe), o bom (wa) e o bem (nawa). E faz sentido que a arte seja ociwa, entre os Nyaneka, com ideia de justiça e virtude num "pensamento bem organizado" ${ }^{86}$ É o caso das tranças de cabelo.

A criação: ompakd ${ }^{87}$ (fabricação) é "criar sabedoria" - paka-ko, ou kolesa e ompakeko designaria o "artista". Isto reúne a ideia de harmonia, virtudes e espírito lógico no habilidoso. Existem vários textos orais (contos, lendas etc.) entre os Nyaneka que melhor explicam de forma intrínseca o que eles entendem por arte e o seu fazedor.

Oci-wa-soke, que entre os Nyaneka designa, de forma genérica, todas as manifestações ou modalidades artísticas (música, dança, escultura, gravura, pintura etc.) é o equivalente ao que a historiografia ocidental terá chamado de arte. Etimologicamente, o termo significa "belo", "bom", "bem" e, ao mesmo tempo, "pensamento" e "inteligência". "Artista” é, literalmente, ompakociwasoke.

\section{"Arte" e "artista" em umbûndu}

\footnotetext{
${ }^{85}$ Hona, yôna, sona (zona?): "pintar”, "desenhar", "escrever".

${ }^{86}$ DIDEROT, D. Euvres complètes, 1976, p. 241; PLATON. Euvres Complètes, 2005, pp.

87 "Criatura” diz-se otyaetwako, ou seja, otyilinga.
} 24-30. 
De acordo com a lexicografia, a arte é definida como: "ofício" = ufuno, ukongo; "habilidade" = olongo, unongo; intelectual = etumba, umesele. ${ }^{88}$

I. "Ofício": ufunu é "habilidade de negociar"; ukôngo "escultura", "algo polido”. Isto é, umateki, utayo).

2. "Habilidade": longo é criador que reflecte, prudente, sábio, habilidoso. Trata-se de fazedor pensador com conhecimento profundo.

3. "Intelectual": tumba ${ }^{89}$ e deriva provavelmente de tumba, fazer (ciclo). Umesele (mesene, em kimbûndu) é "mestre", "artista", "professor" etc.

Numa primeira leitura, as inverdades semânticas permanecem e, por outro, a leitura semiótica diverge: em princípio, a reflexão é para inventar. Tranças de cabelo entre os Nyaneka revelam uma actividade intelectual. ${ }^{\circ 0}$ Os Umbûndu consideram o artista além da habilidade - ondulukiyi, onduvikiyi, onongoloba na presunção de que seja um equilibrador da ordem (luliko) tensões. As responsabilidades sociais do ondulukiyi (artista) faz dele um activista socia $\sqrt{22}$ e líder de opinião, com autoridade moral amplamente consentida.

\section{"Arte" em kikôngo}

Na herança semântica em kikôngo, há quatro linhas em ter com conta: (i) elite, filósofo e intelectual caracteriza o artista: mwêsa; (ii) belo, bem e o bom caracteriza a arte: mpwe; (iii) símbolos sociais da liberdade: nkêta; (iv) "não-eu" como finalidade dos valores. Desenha-se aqui o campo artístico.

Geralmente, o êxtase provocado pela arte faz do seu criador um ñgânga. Isto é, conhecedor habilidoso e impulsionador de alegria/prazer, mas também, de tristeza/dissabor. A incorruptibilidade que o artista expressa através da sua ideia

\footnotetext{
${ }^{88}$ GUENNEC, G.; VALENTE, J.F. Dicionário umbundu-português, 1972, p. 6 o.

${ }^{89}$ ALVES, A., op. cit., pp. 356, 992 e 555.

${ }^{\circ}$ Diferenciam-se tranças para solteiros, casados, iniciados em diferentes sociedades, poliandra, polígamo, viúvo, caçador etc. Cada trança é um texto específico.

${ }_{91}$ GUENNEC, G.; VALENTE, J.F. Dicionário umbundu-português, p. 6o; ALVES, A. Op. cit., p. 57I.

${ }^{92}$ FOUCAULT, M. Cours au Collège de France. Paris, 2006, p. 188.
} 
material lustra a rugosidade da ordem dos homens. Arte codifica as virtudes que diluem a insensibilidade da injustiça promovida a partir da subconsciência social. Tal é o caso de escultura e "som articulado". O artista estimula mudança ao iluminar a sociedade pela explicação de novos códigos de saber, pelo novo método de viver que revisita a consciência com sugestão da ética da razão. Tal é o caso do mpovi (retórica).

O filósofo Plotino é da opinião de que

o desejável de que não podemos apreender nem a figura, nem a forma, é o mais desejável; o amor que por ele temos é sem medida; sim, o amor é aqui sem limites; a sua beleza é duma outra espécie que não a beleza; é uma beleza acima da beleza. ${ }^{93}$

Talvez uma clarificação que seja útil: o amor enquanto experiência vivida é diferente do amor enquanto finalidade, mas ambas as vertentes são indissociáveis para corporizar o belo. A escultura Ñtoni Malawn ${ }^{94}$ ou Mwêne kông ${ }^{95}$ explicam bem isso que pela semântica destes termos quer pela morfologia escultórica de cada um.

a) Conceito de bom

A. Coene traduz "arte" por umbângu. .6 $^{6}$ ou seja, wuvângu, ao associar wu, prefixo de qualidade, a bângu, ou vângu, que deriva de vânga, "criar", "fabricar", "fazer". O mvângi (feitor) seria então o artista. Esse kikôngo vulgar foi forjado na perspectiva ocidental.

O "que é bom" é, em kikôngo, mbôte, que deriva do termo bota: "I) acalmarse; 2) ser forte, resistir; 3 ) ser próspero" "977 Este termo mbôte implica as seguintes noçôes: I) "bondade (doçura)"; 2 ) "benfeitora". Quanto é utilizado como adjectivo, significa: I) "bom, bem”; 2) “admirável, agradável”; 3) “superior”; 4)

${ }_{93}$ BAYER, R. História da estética. Lisboa: Edições Estampa, 1995, p. 82.

${ }_{94}$ Trata-se de uma pequena estatueta de Santo António kongolizado ou de crucifixo feminizada.

${ }^{55}$ Muito conhecida como maternidade, trata-se de uma rainha a amamentar o povo.

${ }^{6}$ COENE, A. Kikôngo notions gramaticales: vocabulaires français-kikôngo-néerlandaislatin. Mission Catholique Tumba, 1960, p. 26.

${ }^{97}$ LAMAN, K.E. Dictionaire likongo-français. Bruxelas: I.R.C.B., p. 56. 
"bonito, lindo"; 5) “exacto, nobre, aquietável, púdico"; 6) "útil, de bom gosto". Em umbûndu, mboto é "pessoa pacífica" ${ }^{98}$ Etimologicamente, mbôte é "fôlego (bondade/pudor) de Nzâ-ya-mbi” tido como consciência no mûntu, a bondade, a equitabilidade, a alegria consigo mesmo (espírito) e, sobretudo, a esperança. Isto é, a arte tem uma finalidade na construção personalidade do indivíduo. Essa finalidade já foi objecto de análise em Nietzsche $9^{99}$ cuja comparação é a seguinte:

\begin{tabular}{cc}
\hline Kôngo & Nietzsche \\
\hline Bom = agradável $($ mbôte $)$ & Bom = aumento/sensação/vontade de poder \\
Bom = natural/consequencial & Bom = experiencial $/$ consequencial \\
Bom $=$ suporte vital & Bom = necessidade social \\
\hline
\end{tabular}

Pois a noção de "beleza" entre os Kôngo é de suporte vital, o que implica uma beleza per si, que nasce quer com a natureza quer na natureza desse muntu, o suposto depositário do fôlego/mbote de Nzâmbi (símbolo da paz, simetria, criação etc.). Tudo o que é arte é feito pelo ñtima, bons sentimentos, racionalidade, e não pelo môyo, que não abarca estes últimos. A expressão mpwe não só designaria arte/beleza, em todas as modalidades (música, dança, dança teatral, retórica etc.), mas, sobretudo, o que é interessante, encerra o conceito da mestria, intelectualidade e de ordem/harmonia. Ele implica a racionalidade, a bondade, a ordem, a experiência, a grandeza, de modo que, para os Kôngo, é a essência do ntîma.

Salientamos, antes de mais, que o interpretador é aqui isolado na trilogia significante, significado e exegese/interpretador. Entre mpwe (signo), que provoca alguma emoção daquilo que é nya (representa), e mpwenya (significado), que sequencia a multileitura de um factio (teoria de Pierce), haveria, porém, uma congruência de hermenêutica na completude da arte caso a exegese/interpretador se assumisse como o terceiro elemento, o qual aprecia a obra de arte a partir da sua origem. A arte mpwe implica que nya proporciona "sentimento" (triste ou alegre) e que assuma a função sintáctica de objecto. A pragmática praxiológica

${ }^{98}$ A frase: "tjimboto upula omala" = "Pessoa pacífica ( $\left.t j i-m b o t o\right)$ pergunta-lhe pelos miúdos". (ALVES, A. Dicionário etimológico bundo-português, Lisboa: Centro Tipogr. Colonial, 1951, p. 686).

${ }^{99}$ NIETZSCHE, F. A filosofia na época trágica dos gregos. Lisboa: Edições 70, p. 45. 
faculta-nos leitura de mpwenya (beleza prática). O princípio é "o significante e o significado são simultâneos, enquanto [sic] o antecedente e o consequente são sucessivos”. Desta feita, mpwe passa a ser, segundo esta lógica, corpóreo, mas notamos a sua extensão em nya (belo). Isto é, assume parcialmente ser incorpóreo, contrariamente à teoria todoroviana, segundo a qual, "o significante é 'corpóreo' ao passo que o antecedente, sendo uma proposição, é 'incorpóreo'”.

O que é mpwe implica racionalidade, bondade, ordem, experiência e grandeza. Para nye é racionalidade, afeição, harmonia, mestria e intelectualidade. Racionalidade e bondade (bons sentimentos) constituem o epicentro da arte, na concepção e prática. Isto é, o objectivo de mpwenya é buscar a harmonia e ordem na sociedade, mas inicialmente foi tido como obra apenas de pessoas com experiência (mestria) e intelectualidade, que tinham em vista o bem-estar social. Ou seja, devem ser mestres, autores da obra de arte porque esta surge como o produto da experiência.

\section{Conclusão}

Parece-nos interessante frisar aqui a beleza tal como expressa pela herança linguística e produção artística. Ela não se dissocia da razão e da bondade. O ser humano - ou seja muntu, omuntu - é um ser bondoso por natureza, e só pode assim ser considerado por corporizar a razão (é dotado de inteligência). Para nós, a dialéctica da beleza (razão/bondade) expressa largamente na vida quotidiana dos Bantu - o que levou Placide Tempels a teorizar a filosofia bantu - está patente nas obras de arte clássica que encontramos nos museus de Antropologia, do Dundo, em Angola, ou ainda no Museu do Quai Branly que a chamou de "arte primeira”.

\section{Referências}

ALVES, A. Dicionário etimológico bundo-português, Lisboa: Centro Tipogr. Colonial, I95I.

APPIAH, K. In my father's house. Nova York: Oxford University Press, 1992. BARBOSA, A. Dicionário cokwe-português. Lisboa: Junta de Investigações do Ultramar, 1989. 
BATSÎKAMA, P. Mbôngia ñgîndu. Escola das Ciênciaspoliticas no antigo Kôngo. Luanda: Mayamba, 2019.

BAYER, R. História da estética. Lisboa: Edições Estampa, 1995.

BENVENISTE, E. Les vocabulaires des institutions indo-européenes. Paris: Seuil, I975.

BIDIMA, J-G. Théorie critique et modernité négro-africaine: de l'École de Francfort à la "Docta spes africana", Philosophie. Paris: Publications de la Sorbonne, I993.

BIGONGIARI, D. (ed.). The political ideas of St. Thomas Aquinas. Nova YorkHafner, 1963.

COENE, A. Kikôngo notions gramaticales: vocabulaires français-kikôngo-néerlandais-latin. Mission Catholique Tumba, 1960.

COSTA \& al. Dicionário de lingua portuguesa. Porto: Porto Editora, 1998.

CROS, E. Le sujet culturel: sociocritique et psychanalyse. Paris/Torino/Budapest: L'Harmattan, 2005.

CUVELIER, J. Nkkutama mvilza za makanda mu nsia Kôngo. Tumba: Diocèse de Matadi, I934.

DEWEY, J. Art as experience. Nova York: Perigee Trade, 2005.

DICKIE, G. "What is art?". In: AAGAARD-MOGENSEN, L. (ed.). Culture and art. Atlantic Highlands, N. J.: Humanities Press, 1976.

DIDEROT, D. Euvres complètes, Tomes V-VIII. Paris: Herman, 1976.

ESTERMANN, E. Etnografia do sudoeste de Angola. I. Os povos não-bantos eo grupo étnico dos ambos. Lisboa: Junta de Investigações do Ultramar, 1956.

EWING, A.C. As questôes fundamentais da filosofia. Rio de Janeiro: Zahar, 1984. FOUCAULT, M. Cours au Collège de France. Paris, 2006.

GUENNEC, G.; VALENTE, J.F. Dicionário umbundu-português. Luanda: Instituto de Investigação Científica de Angola, 1972.

GYEKYE, K. African philosopbical thought. Cambridge: CUP, 1987.

HEGENBER, L. Dicionário de lógica. São Paulo: E.P.U., 1995.

HOLANDA, F. Diálogos de Roma. Lisboa: Livros Horizonte, 1984.

HOUNTONDJI, P. Sur la philosophie africaine. Paris: Maspero, 1976.

KAGAME, A. La philosophie bantou-rwandaise de l'être. Bruxelas : ARSOM, 1956. 
LAMAN, K.E. Dictionaire likongo-français. Bruxelas: I.R.C.B., 1936.

MILLET, L. La métaphysique. Paris: PUF, 1996.

MUDIMBE, V. Y. The invention of Africa: gnosis, philosophy, and the order of knowledge. Bloomington: Indiana University Press, 1988.

NIETZSCHE, F. A filosofia na época trágica dos gregos. Lisboa: Edições 70, 2006. PLATON. CEuvres complètes. Paris: Flammarion, 2005.

SALMON, W. C. Lógica. Rio de Janeiro: LTC Editora, 20 o.

SCHOPENHAUER, A. Sobre a vontade na natureza. Porto Alegre: L\&PM, 2013.

SILVA, A.J. Dicionário nhaneca-português. Lisboa: Junta de Investigações Científicas de Angola, 1966.

TEMPELS, P. La philosophie bantu. Paris: Présence Africaine, 1948.

THOMPSON, R. F. Flash of the spirit: arte e filosofia africana e afro-americana. São Paulo: Museu Afro Brasil, 2011.

TOWA, M. Essai sur la problmématique philosophique dans l'Afrique actuelle. Yaoundé: CLE, I97I.

VAZ, J. M. Filosofia tradicional dos Cabindas através dos seus cestos de panelas: provérbios, advinhas, fábulas I. Lisboa: Agência Geral do Ultramar, 1959.

Resumo: A discussão estética em torno da dinâmica da produção artística entre a arte clássica (tida como arte tradicional pelos etnólogos coloniais) e a arte contemporânea produzida por africanos (patentes nas galerias da arte) tem sido tímida. Três razões são levantadas. A primeira é a falta de estudos para sua sistematização e classificação. A segunda tem a ver com a polémica a volta da filosofia africana. A terceira versa-se na ausência de pesquisadores nas arenas internacionais para discutir a questão. Depois de ter discutido essa
RÉSUMÉ: La discussion esthétique sur la dynamique de la production artistique entre l'art classique (considéré comme l'art traditionnel par les ethnologues coloniaux) et l'art contemporain produit par les Africains (présentée dans les galeries d'art) semble être timide. Trois raisons sont soulevées. Le premier est le manque d'études pour sa systématisation et sa classification. Le second a avoir avec la controverse autour de la philosophie africaine. Le troisième concerne l'absence de chercheurs dans les arènes internationales 
possibilidade no Congresso Mundial pour discuter de la question. Après de Filosofia (Universidade Nacional de avoir discuté de cette possibilité au Seul, 2008) e no Congresso Internaci- Congrès Mondial de Philosophie (Unional da Estética (Université de Beijing, versité Nationale de Séoul, 2008) et 2013), expomos o presente artigo, esco- au Congrès International d'Esthétique lhemos a discussão sobre filosofia e be- (Université de Peking, 2013), nous préleza na arte clássica em África, optando sentons cet article, nous avons choisi num discurso estético que poderá servir la discussion sur la philosophie et la também para arte contemporânea.

Palavras-chave: Filosofia;

Muntu-angolano; Arte. beauté dans l'art classique de l'Afrique, optant pour un discours esthétique qui peut aussi servir à l'art contemporain.

Mots-CLÉs: Philosophie;

Muntu-angolais; Art. 